\title{
6
}

\section{The NICHD Protocol: Guide to Follow Recommended Investigative Interview Practices at the Barnahus?}

\section{Gunn Astrid Baugerud and Miriam Sinkerud Johnson}

\section{Introduction}

One of the main challenges in cases where child sexual abuse or physical abuse is suspected is that the children are usually the only available sources of information about the experiences (Lamb et al. 1998). Definitive physical, medical or psychological symptoms are lacking or inconclusive in the vast majority of such cases (e.g. Lewis et al. 2014). Without any other witnesses or incontrovertible indications, the suspicion of abuse and the progress of the inquiry often rest upon the child's narrative and the interviewer's ability to maximise the quality and quantity of information obtained from the child.

Over the past 30 years, considerable resources have been invested in the development of professional guidelines for how investigative

G.A. Baugerud ( $\bowtie) \cdot$ M.S. Johnson

Oslo and Akershus University College of Applied Sciences, Oslo, Norway e-mail: Gunn-Astrid.Baugerud@hioa.no

M.S. Johnson

e-mail: Miriam.Sinkerud-Johnson@hioa.no

(C) The Author(s) 2017 
interviewers should conduct interviews with children who are suspected victims of sexual or physical abuse, or witnesses to crimes. Considerable efforts have been made to understand how children's testimony can be made as useful and accurate as possible (Lamb et al. 2007).

An important change in child investigative interviewing within the Nordic countries was the establishment of the Barnahus model where interviews and medical examinations are delivered under one roof in a child-friendly environment. The Barnahus model is based on the principle that such child-friendly, interdisciplinary and multiagency responses to child abuse could enhance the quality of the investigative interviews (see the introduction chapter of this book). An important goal in order to enhance the quality of investigative interviews has been to take a closer look at interview practices and the techniques used in the interviews. The justice systems in Finland, Iceland and Sweden use methods inspired by the Protocol of the National Institute of Child Health and Human Development (NICHD) (Lamb et al. 2007; Orbach et al. 2000) when conducting investigative interviews of child witnesses. The NICHD protocol is based on research and expert professional consensus regarding children's memory, communicative skill and social knowledge, which has been translated into guidelines that aim to improve the quality of forensic interviews of children.

In this chapter, we will outline the main features and empirical background of the development of the NICHD Investigative Interview protocol. We also present a revision of the NICHD protocol, which has been designed to help interviewers to provide non-suggestive support to alleged victims who might be reluctant to make allegations of abuse.

\section{Improving the Quality of Investigative Interviews with Alleged Child Victims}

Since the early 1990s, highly publicised child sexual abuse cases, such as the McMartinand Kelly Michaels Cases in the USA, the Bjugn case in Norway and the Cleveland case in the UK, have drawn attention to inappropriate interview strategies and the counterproductive ways in which alleged victims are sometimes interviewed (Bruck 1999). 
The lack of coordination among the agencies involved and the use of repeated interviewing with different interviewers, as well as stressful and compromising environments for the child when interviewed, were serious shortcomings in the field of investigative interview practice (Ceci and Bruck 1993; Cross et al. 2007). Researchers have shown that child investigative interviewing within Children's Advocacy Centres (CAC) seems to offer a more thorough child-focused response to children's reports, and the families involved seem to have more positive experiences (Cross et al. 2007). The American model (CAC) inspired the development of the Barnahus model in the Nordic countries to a large extent. The Barnahus model aims to reduce the stress of the legal process for children and their families, to increase the level of cooperation between professionals and to build and disseminate knowledge regarding victimised children (Bakketeig et al. 2012). Researchers have repeatedly shown that the quality of interviewing reliably improves dramatically when interviewers employ structured investigative interview protocols (e.g. Lamb et al. 2007). In Sweden, Iceland and Finland, where the Barnahus model has been implemented, police officers or psychologists are inspired by the NICHD protocol when conducting child forensic interviews. The NICHD protocol (Lamb et al. 1998, 2007; Orbach et al. 2000) is currently used in training of police officers and other criminal justice system practitioners in many different countries and is one of the most internationally used protocols for interviewing child witnesses.

\section{NICHD Investigative Interview Protocol}

A major purpose of the NICHD protocol was to translate the recommendations resulting from research into operational steps that would improve the organisation and quality of investigative interviews with children and increase the likelihood of obtaining complete and precise information. By helping interviewers conduct interviews that are more informative, the protocol is designed to promote children's wellbeing by facilitating the prosecution of offenders. The NICHD protocol was developed with reference to child development issues, including 
linguistic abilities, memory retrieval capacities, suggestibility, interviewer behaviour and the effects of stress and trauma. For example, the protocol integrates recent knowledge about memory functions and the suggestibility of children and is used with children who are suspected of having been sexually or physically abused.

\section{Children's Memory Development}

After children have disclosed the abuse, their memories of the event become very important if the case is going to court. Basic and applied research into children's memory development has been crucial in helping police and social welfare workers to conduct better child investigative interviews. Different factors influence a child's experience of an abusive event, and knowledge about how children encode, store and retrieve stressful events from the past is of vital importance (e.g. Lamb et al. 2011). Indeed, we all depend on our memory when we need to answer questions about experiences.

Memory is believed to be a multiple system composed of encoding arrangements or subsystems, storage and information recovery (e.g. Baddeley et al. 2011; Tulving 1985). In the past two decades, there has been growing consensus that memory is not a unified ability but rather a set of dynamic, integrated systems (e.g. Squire 2004).

The study of children's memory and factors influencing children's memory performance have been studied within a broad context in the past several years and is influenced by enhanced knowledge about cognitive maturity such as the development of language, perception, recognition and encoding (e.g. Lamb et al. 2011). Most theories distinguish between explicit and conscious memories, and memories not accessed by conscious recall (Goswami 2008). Autobiographical memory involves explicit memories of specific times and places in an individual's past (Fivush 2011) and depends on several factors such as language ability, neural structures, socio-emotional components, attachment orientation and cognitive development (Bauer and Fivush 2010). Differences in autobiographical memory across age groups have an important impact on memory capacity in terms of the memory retrieval strategies 
of preschoolers and older children. Fivush (2011) suggests that autobiographical memory is a system which develops gradually during childhood and depends on the individual's development of their sense of self. The awareness of self (i.e. "I" and "me") is first available around the age of two and facilitates what becomes an autobiographical memory (Howe 2003). Empirical studies have shown that events, including traumatic ones that occur before the age of 2-3 years are unlikely to be available for conscious verbal recall (Cordon et al. 2004; Newcombe et al. 2007; Simcock and Hayne 2002). This phenomenon is usually referred to as "infantile amnesia" and has been validated by over a century of empirical research (Bauer 2007; Josselyn and Frankland 2012). By the age of three, however, children's recall of stressful events can be consistent and robust (Peterson and Warren 2009), and they are able to recall stressful negative events over time, as well as reporting new correct information (Baugerud et al. 2014; Lamb et al. 2011).

\section{Age Differences and Memory}

The most important individual difference in children's memory is connected to their age (Schneider and Bjorklund 2003). In general, preschool children recollect less information, provide briefer accounts and tend to forget more rapidly than older children (Schneider and Bjorklund 2003; Ornstein et al. 1997). Preschoolers have more limited language comprehension and communication abilities due to more limited vocabularies and retrieval strategies than older children and adults (Schneider and Pressley 2013). Increasing age brings with it increasing sophistications in the exercise of strategic memory skills, such as rehearsal, use of mental imagery and semantic organisation (Schneider and Pressley 2013). That said, other causes such as experiences with abuse or concurrent stressors leading to psychopathology, lack of appropriate verbal stimulation from parents and the development of an overgeneral memory may all be factors involved in autobiographical memory problems (Greenhoot et al. 2008). Developmental differences are important, but the literature remains inconclusive and younger children may be as accurate as older children (see La Rooy et al. 2011 for a review). 


\section{Interviewer Techniques in Relation to the Quality and Quantity of Children's Response}

Even if children as young as three years of age are able to give coherent verbal reports of both neutral and stressful experiences, research has repeatedly shown that the quantity and quality of children's reports are fundamentally affected by whether interviewers use interview techniques carefully (Brown et al. 2008). These findings have been important for the development of structured interview protocols, such as the NICHD protocol. The consensus among experts regarding how children should be interviewed is that it should involve as much use as possible of free recall and open-ended questions, rather than focused and suggestive prompts (Lamb et al. 2007). Responses to open-ended questions and eliciting free recall encourage more accurate and longer responses from children. On the other hand, suggestive questioning produces shorter reports, which are more likely to be erroneous and may also produce false reports, particularly in preschool children (e.g. Anderson et al. 2014; Craig et al. 1999; Davies et al. 2000; Lamb et al. 2007).

\section{Suggestive Interviewing}

A sizeable body of research has shown how suggestive interview techniques may negatively affect the dynamics of investigative interviews (see Bruck et al. 2002, for a review). Suggestive interviewing is strongly related to the concept of interviewer bias and the expectancy effects that emerge when interviewers with preconceived notions seek to confirm evidence in ways that are related to a priori beliefs and expectations (e.g. Ask and Granhag 2005; Bruck et al. 2002). Children may, for example, tailor their reports by confirming or rejecting information if they infer that interviewers would prefer certain responses (e.g. Bjorklund et al. 2000; Melnyk et al. 2007). Interviewer expectations may affect the way question types are used and explicitly or implicitly be communicated through a variety of option-posing and suggestive techniques that generally request children to confirm or reject options provided by the interviewer. Repeated suggestive questions and reinforcement questions 
(i.e. positive and negative consequences), for example, are believed to be question types that communicate to the child what response is expected and can quickly induce children to make persistent false allegations of wrongdoing (Bruck et al. 2002; La Rooy et al. 2010). Using co-witness information such as peer or parental pressure by telling the child that the interviewer has already received information from another person may also create pressures towards conformity (e.g. Ceci and Friedman 2000). An interviewer's expectations may also influence their nonverbal expressive behaviour (Andrews and Lamb 2014).

Although suggestive techniques might produce accurate abuse reports from otherwise silent children, the same techniques entail a risk of negatively shaping and contaminating children's reports, as the responses to such questions are more likely to be inaccurate. Contradictory or nonsensical responses, which can appear in response to suggestive questioning, may reduce the credibility of the children's account (e.g. Anderson et al. 2014; Howie et al. 2012; Lamb et al. 2013). The detrimental effect of suggestive techniques on children's accuracy is often misused in an attempt to discredit children's testimonies and is likely to be used against the child in court (Goodman et al. 1999).

People of all ages are susceptible to misinformation and can become confused over the source of their memories; however, a common finding across studies is that preschool children in general are more susceptible to the suggestion and distortion of their memories than are older children and adults (e.g. Ceci and Bruck 2006; La Rooy et al. 2009; Ghetti and Alexander 2004). Age differences in suggestibility have also been found in studies that included more realistic situations (e.g. Cassel and Bjorklund 1995; Eisen et al. 2002). During the past 10 years, there has been a shift in research characterised by refocusing on children's competence as witnesses and the conditions under which children's testimonies may be improved and suggestibility reduced. Researchers have shown that even young children can be resistant to suggestive questions and that children's compliance with suggestive techniques is related to the social demand characteristics of the situation (Schneider and Pressley 2013). Researchers have also suggested that interview factors are more important than children's individual 
characteristics in determining resistance to suggestion (Finnilä et al. 2003; La Rooy and Lamb 2011).

\section{The Structure of the NICHD Protocol}

The structure of the NICHD protocol, which is described in detail in several publications by Lamb and colleagues (e.g. Lamb et al. 2007), covers all phases of the investigative interview. In the introductory phase, the interviewer introduces themselves, clarifies the child's task ([a] describes events in detail and [b] asks them to tell the truth) and explains the ground rules of the interview, including the notion that the child can say, "I don't remember" or "I don't understand" or correct the interviewer when appropriate. The following rapport-building phase, which is designed to create a relaxed, supportive environment for children, is introduced with a section where the child is encouraged to describe a recently experienced neutral event in detail. Lamb and colleagues (2007) emphasise that this training section is designed to familiarise children with the open-ended invitations used in the substantive phase while demonstrating the specific level of detail expected of them. Additionally, in a transitional section between the presubstantive and the substantive phases of the interview, a series of prompts that are as open as possible are used to non-suggestively identify the target events under investigation. The interviewer moves on to some carefully worded and increasingly focused prompts only if the child fails to identify the target event/s. If the child makes an allegation, the free recall phase begins with an invitation ("Tell me everything..."), and other free recall prompts or invitations are recommended. As soon as the first narrative is completed, the interviewer prompts the child to indicate whether the incident occurred "one time or more than one time" and then proceeds to secure incident-specific information using follow-up prompts ("Then what happened?") and cued questions (e.g. "Earlier you mentioned a [person/object/action]. Tell me everything about that"), referring to details mentioned by the child to elicit uncontaminated free recall accounts of the alleged incident/s (Lamb et al. 2007, 1204-1205). Only after the exhaustive free recall, do prompting interviewers to proceed to 
focused recall questions that address details previously mentioned by the child and request information within specific categories. If crucial details are still missing, interviewers then ask limited option-posing questions, mostly yes/no or forced-choice questions referencing new issues that the child failed to address previously. Suggestive utterances, which communicate to the child what response is expected, are strongly discouraged (Lamb et al. 2007).

The NICHD protocol has been subjected to more empirical studies than any other interview protocols (e.g. Lamb et al. 2008). Overall, the findings obtained in field implementation studies in Canada ( $\mathrm{Cyr}$ et al. 2012; Cyr and Lamb 2009) and in the UK demonstrate that when investigative interviewers employ recommended interview procedures by following the NICHD protocol, they generally enhance the quality of information elicited from alleged victims of sexual or physical abuse. Interviewers using the NICHD protocol use at least three times more open-ended and half as many option-posing and suggestive questions as they do without the protocol (Lamb et al. 2007). Specifically, the study by Cyr and colleagues (2012) revealed that application of the NICHD protocol effectively increases informative details about child sexual abuse provided by children in response to open-ended questions.

\section{The Revised NICHD Protocol}

When government employees interview children, many of them are reluctant to disclose abuse. This also happens in cases where the police have evidence that the children in fact have been abused (Leander 2007). Some researchers have pointed out that the Standard Protocol (SP) is most useful when children are "active disclosers", that is when children already have, for instance, told a parent or a teacher about sexual abuse (Faller and Everson 2012). Research has shown that disclosure rates have proved to be higher when children are formally interviewed, compared to adults with childhood histories of child sexual abuse, reporting the abuse in retrospective studies, even if there is great variation between different studies (London et al. 2008). This suggests that the skills of the interviewer and 
how to overcome a child's reluctance may be very important, and recent studies have just started to investigate the impact of enhanced socioemotional support in the interview setting when children exhibit reluctance when interviewed (Ahern et al. 2014; Hershkowitz et al. 2013). It seems that interviewer support is particularly important when interviewing children unwilling to talk (Hershkowitz et al. 2006). Because of this, Herschkowitz and colleagues acknowledged the need for a revised NICHD protocol (RP) in order to enhance reports from alleged abused children (Herschkowitz et al. 2014). In the RP, it was important to raise the children's trust and cooperation and there is an increased focus on giving the children socio-emotional support through the interview. The order of the phases in the interview was changed, and the report-building phase precedes the ground rules phase instead of following it. More guidance was also provided to the interviewers to maintain and establish report building, and to encourage the children to disclose. The interviewers were trained to use more support in the presubstantive phase in a non-suggestible and non-leading way (e.g. asking children about their hobbies, what they like to do, etc.) before explaining ground rules (see nichdprotocol.com for a detailed description of the revised protocol). The RP was tested in a large study in Israel in which independent evidence that intrafamilial abuse had taken place was established. The results showed that children were significantly more likely to make allegations of abuse when the revised protocol was employed, compared to the SP (Herschkowitz et al. 2014). These results suggest that emotional support in forensic interviewing may be very important and facilitate accurate reports of abuse by children who might otherwise be reluctant to make allegations (Hershkowitz et al. 2014). In addition, it may be crucial in improving disclosures rates in child forensic interviewing to provide children with calm and supportive environments. Several factors, such as the interview itself, the child's age and gender and caregiver support, could all affect whether children disclose or not (Goodman et al. 2014) but the context in which the children are interviewed may also be very important and the Barnahus model provides a safe and child-friendly setting, which may lower children's stress and make them more relaxed. Studies have consistently shown that greater arousal during the retrieval of memories inhibits memory (Roozendaal et al. 2009; Smeets et al. 2008) and being interviewed at a Barnahus may reduce stress 
and make children more comfortable in the interview setting. This in turn may allow them to use cognitive resources to make a memory search and/ or focus on the interviewer's questions (Goodman et al. 2014; Quas et al. 2004; Rush et al. 2014). The RP particularly highlights the importance of interviewers responding more sensitively and using supportive comments with reluctant children (Ahern et al. 2014). In summary, the high standards of the Barnahus that take the abilities, vulnerabilities and needs of child witnesses into account, combined with the use of RP in interviewing, may be very important in enhancing the disclosure rates of maltreated children.

In a recent study employing the $\mathrm{RP}$, an extended training programme for interviewers was developed and tested (Hershkowitz et al. unpublished manuscript). The researchers used an evidence-based training programme which included more detailed guidance for interviewers and how they could support children reluctant to disclose. The format included a train - the trainer approach in which inexperienced interviewers received training from more experienced interviewers under the supervision of researchers. This training involves teaching interviewers to code their own interviews systematically as well as train, supervise and monitor the skills of others. A feedback system for self-identifying support was also included. This helped the interviewers recognise children's expressions of distress or reluctance (for a more detailed description see Hershkowitz et al. unpublished manuscript). The results showed that the level of support increased among the interviewers and instances of inadequate support and insensitivity to children's reluctance became less common. These effects can have important consequences for disclosure rates and avoid incidents of child abuse remaining unreported. The study shows encouraging results in that continued supervision and training might be very helpful in enhancing the competence of the forensic interviewers (Hershkowitz et al. unpublished manuscript). Several factors such as intrafamilial relations, loyalty to family members, fear, the severity of abuse, feelings of embarrassment and shame, perceptions of responsibilities and worries about legal consequences may prevent children from the disclosure of abuse. For example, research has indicated that children are less likely to disclose if the perpetrator is a close family member (Arata 1998; Goodman-Brown et al. 2003; 
London et al. 2005). More supportive interviewing, through the use of the revised protocol, may reduce reluctance in these children and yield higher rates of allegations by young children, compared to children who still are interviewed with the SP.

It is important to continue to conduct more research with the RP model to further evaluate the model and to include physical as well as sexual abuse cases. All the different approaches that are endorsed for interviewing children should be evaluated and evidence based to ensure the quality in interviewing. Most important is that research-based guidelines are used when professionals are interviewing children.

\section{Importance of Interviewer Training}

There has been an awareness in the last 15-20 years of the importance of following the evidence-based recommendations and that interviewers should be trained in accordance with best-practice recommendations; however, a growing body of field studies that have examined investigative interviews conducted in Israel (Hershkowitz et al. 2005), the UK (Westcott and Kynan 2006), Australia (Agnew et al. 2006; Guadagno and Powell, 2009), the USA (Sternberg et al. 1996), Canada (Cyr and Lamb 2009), Sweden (Cederborg et al. 2000), Finland (Korkman et al. 2006; Santtila et al. 2004) and Norway (Johnson et al. 2015) suggests that investigative interviewers generally fall short of capturing bestpractice evidence-based recommendations. In fact, regardless of country and investigative culture, the widespread tendency is for interviewers to rarely use open-ended questions that invite free narratives and instead rely heavily on option-posing, leading and suggestive prompts. Overall, studies have revealed a notably low frequency of open-ended invitations, ranging from 2 to $6 \%$, regardless of the children's age and the nature of the alleged offences. The distribution of non-recommended techniques, such as option-posing and suggestive questions, was in turn quite high, often as high as $50 \%$ of the questions asked.

Although the use of suggestive interview techniques is generally assumed to be associated with untrained interviewers, similarly poor interviewing techniques have been observed in studies involving 
interviewers had received specialised training to improve their interview skills. Researchers have suggested that inappropriate questioning and poorly structured interviews are still dominant even when investigators have received specialised training and understand the conceptual issues of appropriate interviewing (e.g. Aldridge and Cameron 1999; Lamb 2016; Lamb et al. 1996; Sternberg et al. 2001; Warren et al. 1999). Brief initial training programmes appear to be insufficient even when police investigators are trained in knowledge such as the way human memory works, effective communication and proper interview techniques. These findings indicate that training programmes may not be as effective as presumed in reducing the amount of non-recommended questioning. Nevertheless, recent studies have shown that interviewer behaviour can be improved under systematic and intensive training conditions (e.g. Cederborg et al. 2013; Cyr and Lamb 2009; Davies et al. 2000; Lamb et al. 2011). For example, Lamb et al. (2002) concluded that organised feedback and follow-up sessions led to better investigative interviewing in terms of a significant reduction in unfortunate interviewing techniques.

In future studies, it will be important to carry out more evaluations using different approaches; however, despite the positive effects in terms of improved interviewer behaviour, few researchers have so far succeeded in showing enduring structural behavioural changes after the course of training has ended. In Norway, we will assess the interview model currently being used by evaluating the quality of a national sample of investigative interviews of suspected child sexual abuse and violence victims conducted at Barnahus during the past five years (2012-2017). After new regulations in Norway in 2015, all child forensic interviews are carried out at the Barnahus. It is possible that the Barnahus model contributed to children being less upset and stressed when the interviews are conducted and thus enhancing the quality of the interviewer practices, and thus led to more positive case outcomes. In line with similar studies, the quality of investigative interviews refers to the identification of the various elements of what takes place in these encounters, with special emphasis on analysing the content of interview strategies employed. This content analysis especially aims to measure the proportional differences between recommended and non-recommended questioning employed by interviewers in these situations, and how these 
relate to the content of the accounts provided by children. This will be addressed by examining different aspects of the responses by children in detail in relation to the forms of questioning employed in forensic interview situations. The quality of investigative interviews should also emphasise aspects of the social dynamics that develop in investigative interviews and the way these factors ultimately affect the quality of the information obtained from the child. The focus on developing interviewing skills in future training programmes of evidential investigative practice should emphasise aspects of interviewer behaviour and interviewer-respondent interaction in the interview setting, towards better compliance with internationally recognised guidelines. The quality of investigative interviews with vulnerable witnesses, such as preschool children and youths with intellectual disabilities, is entirely unknown. In future research, we need to know more about the ways in which vulnerable groups are interviewed and how these groups of witnesses provide information when interviewed about their abuse experiences.

\section{The Barnahus: A Universal Model to Improve the Response to Child Abuse}

The overarching goal of this chapter was to present the investigative interview protocol currently being used in most of the Nordic countries where the Barnahus model has been implemented.

The Barnahus model offers a child-friendly context that provides extended support to the children and their families, medical examinations, and the follow-up of treatment needs and mental health services that are important in taking care of abused children. The child-friendly facility that the Barnahus model provides may help the children be less distressed, as in providing more support the children typically become more comfortable and less aroused. This may create a better context than other arrangements for children when interviewed. Alleged offenders are not permitted to be in the area, interview rooms are private, and senior counsellors/psychology specialists from the Barnahus perform a monitoring role and assess the child's mental health as the interview is conducted, as well as ensuring that the child need only to describe their 
experience. There may also be follow-up interviews if needed. This is very important for determining what further treatment and follow-up are required. There is a reason to believe that the child-friendly environment in the Barnahus model can facilitate the use of structured interview protocols by providing optimal conditions for the children to talk about their own experiences.

Research findings have provided strong support for the effectiveness of the NICHD protocol. There are new promising findings for children who are unwilling to disclose abuse, using the revised protocol, and further research will show whether increased use of support will help children's reluctance to be less common; however, we must also recognise that children need to feel comfortable, and that creating a child-friendly setting is indeed important in order to provide the optimal conditions for children to provide accurate and detailed accounts of distressing and traumatic events. The Barnahus model ensures such environments and makes sure that children are cared for in the best way.

Contributions from three decades with practice and international research in relation to child investigative interviews have provided valuable knowledge when it comes to improving responses to child abuse in the Nordic countries. Future research should continue to evaluate the different models and adhere to evidence-based child interview strategies as this can optimise children's recall and as such have important implications for both legal and appropriate treatments of children.

\section{References}

Agnew, Sarah, Martine Powell, and Pamela Snow. 2006. An examination of the questioning styles of police officers and caregivers when interviewing children with intellectual disabilities. Legal and Criminological Psychology 11: 35-53.

Ahern, Elizabeth, Irit Hershkowitz, Michael Lamb, Uri Blasbalg, and Alice Winstanley. 2014. Support and Reluctance in the Pre-substantive Phase of Alleged Child Abuse Victim Investigative Interviews: Revised versus Standard NICHD Protocols. Behavioral Sciences \& the Law 32 (6): 762-774. 
Aldridge, Jan, and Sandra Cameron. 1999. Interviewing Child Witnesses: Questioning Techniques and the Role of Training. Applied Developmental Science 3: 136-147.

Anderson, Gwendolyn, Jessica Anderson, and Jane Gilgun. 2014. The Influence of Narrative Practice Techniques on Child Behaviours in Forensic Interviews. Journal of Child Sexual Abuse 23: 615-634.

Andrews, Samantha. J., and E. Michael Lamb. 2014. The effects of age and delay on responses to repeated questions in forensic interviews with children alleging sexual abuse. Law and Human Behavior 38: 171-180.

Arata, Catalina.M. 1998. To Tell or Not to Tell: Current Functioning of Child Sexual Abuse Survivors Who Disclosed Their Victimization. Child Maltreatment 3: 63-71.

Ask, Karl, and Pär-Anders Granhag. 2005. Motivational Sources of Confirmation Bias in Criminal Investigations: The Need for Cognitive Closure. Journal of Investigative Psychology and Offender Profling 2: 43-63.

Baddeley, Alan D., Michael C. Anderson, and Michael W. Eysenck. 2011. Memory. PortoAlegre: Artmed.

Bakketeig, Elisiv, Mette Berg, Trond Myklebust and Kari Stefansen. 2012. Barnehusevalueringen. Delrapport 1. Barnehusmodellens implikasjoner for politiets arbeid med fokus på dommeravhør og rettsmedisinsk undersøkelse. PHS forskning 6. Oslo: PHS.

Bauer, Patricia, and Robyn Fivush. 2010. Context and Consequences of Autobiographical Memory Development. Cognitive Development 2: 303-308. Bauer, Patricia. 2007. Recall in Infancy A Neurodevelopmental Account.

Current Directions in Psychological Science 16 (3): 142-146.

Baugerud, Gunn Astrid, Svein Magnussen, and Annika Melinder. 2014. High Accuracy but Low Consistency in Children's Long-term Recall of a Real-life Stressful Event. Journal of Experimental Child Psychology 126: 357-368.

Bjorklund, David, S. William Cassel, Barbara Bjorklund, Rhonda Brown, Cynthia Park, Kim Ernst, and Felicia Owen. 2000. Social demand characteristics in children's and adults' eyewitness. Applied Cognitive Psychology 14: 421-433.

Brown Deirdre, Michael Lamb, Margaret-Ellen Pipe and Yael Orbach. 2008. Pursuing the Truth the Whole Truth and Nothing but the Truth Forensic Interviews with Child Victims or Witnesses of Abuse. In Stress Trauma and Children's Memory Development Neurobiological Cognitive Clinical and legal perspectives, eds. Mark L. Howe, Gale S. Goodman and Dante Cicchetti. Oxford: Oxford University Press.

Bruck, Maggie, and Stephen Ceci. 1999. The Suggestibility of Children's Memory. Annual Review of Psychology 50: 419-439. 
Bruck, Maggie, Stephen Ceci, and Helene Hembrooke. 2002. The nature of children's true and false narratives. Developmental Review 22: 520-554.

Cassel, William, and David Bjorklund. 1995. Developmental patterns of eyewitness memory and suggestibility: An ecologically based short-term longitudinal study. Law and Human Behavior 19: 507-532.

Ceci, Stephen, and Maggie Bruck. 2006. Children's Suggestibility: Characteristics and Mechanisms. Advances in Child Development and Behavior 34: 247-281.

Ceci, Stephen, and Maggie Bruck. 1993. Suggestibility of the Child Witness: A Historical Review and Synthesis. Psychological Bulletin 113 (3): 403-439.

Ceci, Stephen. J., and Richard Friedman. 2000. The suggestibility of children: Scientific research and legal implications. Cornell Law Review 86: 34-108.

Cederborg, Ann-Christin, Charlotte Alm, Djaildes Lima da Silva Nises, and Michael Lamb. 2013. Investigative Interviewing of Alleged Children-An Evaluation of a New Training Programme for Police Officers in Sweden. Police Practice and Research: An International Journal 14: 242-254.

Cederborg, Ann-Christin, Yael Orbach, Kathleen Sternberg, and Michael Lamb. 2000. Investigative Interviews of Child Witnesses in Sweden. Child Abuse and Neglect 24: 1355-1361.

Cordón, Ingrid, Mararet-Ellen Pipe, Liat Sayfan, Annika Melinder, and Gail Goodman. 2004. Memory for Traumatic Experiences in Early Childhood. Developmental Review 24: 101-132.

Craig, Ron, A. Rick Scheibe, David C. Raskin, John C. Kircher, and David H. Dodd. 1999. Interviewer Questions and Content Analysis of Children's Statements of Sexual Abuse. Applied Developmental Science 3: 77-85.

Cross, Theodore, Lisa Jones, Wendy Walsh, Minique Simone, and David Kolko. 2007. Child Forensic Interviewing in Children's Advocacy Centers: Empirical Data on a Practice Model. Child Abuse and Neglect 31: 1031-1052.

Cyr, Mireille, and Michael Lamb. 2009. Assessing the Effectiveness of the NICHD Investigative Interview Protocol when Interviewing Frenchspeaking Alleged Victims of Child Sexual Abuse in Quebec. Child Abuse and Neglect 33: 257-268.

Cyr, Mireille, Jacinthe Dion, Pierre McDuff, and Karine Trotier-Sylvain. 2012. Transfer of skills in the context of non-suggestive investigative interviews: Impact of structured interview protocol and feedback. Applied Cognitive Psychology 26: 516-524.

Davies, Graham, Helen Westcott, and Noreen Horan. 2000. The impact of questioning style on the content of investigative interviews with suspected child sexual abuse victims. Psychology, Crime \& Law 6: 81-97. 
Eisen, Mitchell, Jianjian Qin, Gail Goodman, and Suzanne Davis. 2002. Memory and suggestibility in maltreated children: Age, stress arousal, dissociation, and psychopathology. Journal of Experimental Child Psychology 83: $167-212$.

Faller, Coulborn, and Mark Everson. 2012. Contested Issues in the Evaluation of Child Sexual Abuse Allegations: Why Consensus on Best Practice Remains Elusive. Journal of Child Sexual Abuse 21: 3-18.

Finnilä, Katarina, Nina Mahlberg, Pekka Santtila, kenneth Sandnabba, and Pekka Niemi. 2003. Validity of a Test of Children's Suggestibility for Predicting Responses to Two Interview Situations Differing in Their Degree of Suggestiveness. Journal of Experimental Child Psychology 85: 23-49.

Fivush, Robyn. 2011. The Development of Autobiographical Memory. Annual Review of Psychology 62: 559-582.

Ghetti, Simona, and Kristen Alexander. 2004. If it happened, I would remember it: Strategic use of event memorability in the rejection of false autobiographical events. Child Development 75: 542-561.

Goodman, Gail, Deborah A. Goldfarb, Jia Chong and Lauren GoodmanShaver. 2014. Children's Eyewitness Memory: The Influence of Cognitive and Socio-Emotional Factors. Roger Williams University Law Review 19(2), Symposium: Child Witnesses in Sexual Abuse Cases. Article 7.

Goodman, Gail, Jodi Quas, Josephine Bulkley, and Cheryl Shapiro. 1999. Innovations for Child Witnesses: A National Survey. Psychology, Public policy and Law 5: 255-281.

Goodman-Brown, Tina, Robin Edelstein, Gail Goodman, and David Gordon. 2003. Why Children Tell: a Model of Children's Disclosure of Sexual Abuse. Child Abuse and Neglect 27: 525-540.

Goswami, Usha. 2008. The Development of Memory. In Cognitive Development: The Learning Brain, ed. U. Goswami, 250-293. Hove and New York: Psychology Press, Taylor \& Francis Group.

Greenhoot, Andrea, Sarah Bunnell, Jennifer Curtis, Jennifer, and Alisa Beyer. 2008. Trauma and Autobiographical Memory Functioning. Findings from a Longitudinal study of Family Violence. In Stress, Trauma, and Children's Development. Neurobiological, Cognitive, Clinical and Legal Perspectives, eds. M.L. Howe, G.S. Goodman, and D. Cicchetti, 139-170. Oxford: Oxford University Press.

Guadagno, Belinda, and Martine Powell. 2009. A qualitative examination of police officers' questioning of children about repeated events. Police Practice and Research 10: 61-73. 
Hershkowitz, Irit, Elizabeth Ahern, Michael Lamb, Uri Blasbalg, Yael KarniVisel and Michael Breitman. (Unpublished manuscript). Changes in Interviewers' Use of Supportive Techniques During the Revised Protocol Training.

Hershkowitz, Irit, Dvora Horowitz, and Michael Lamb. 2005. Trends in children's disclosure of abuse in Israel: A national study. Child Abuse \& Neglect 29: 1203-1214.

Hershkowitz, Irit, Michael Lamb, and Carmit Katz. 2014. Allegation Rates in Forensic Child Abuse Investigations: Comparing the Revised and Standard NICHD Protocols. Psychology Public Policy and Law 20 (3): 334-336.

Hershkowitz, Irit, Michael Lamb, Carmit Katz, and Lindsay Malloy. 2013. Does Enhanced Rapport-building Alter the Dynamics of Investigative Interviews with Suspected Victims of Intra-familial Abuse? Journal of Police and Criminal Psychology 30 (6): 6-14.

Hershkowitz, Irit, Yael Orbach, Michael Lamb, Kathleen Sternberg, and Dvora Horowitz. 2006. Dynamics of Forensic Interviews with Suspected Abuse Victims Who Do Not Disclose Abuse. Child Abuse Neglect 30 (7): 753-769. Howe, Michael. 2003. When Autobiographical Memory Begins. Developmental Review 23: 471-494.

Howie, Pauline, Laura Nash, Nadezhda Kurukulasuriya, and Alison Bowman. 2012. Children's event reports: Factors affecting responses to repeated questions in vignette scenarios and event recall interviews. British Journal of Developmental Psychology 30: 550-568.

Johnson, Miriam, Svein Magnussen, Christian Thoresen, Kyrre Lønnum, Lisa Victoria Burrell, and Annika Melinder. 2015. Best Practice Recommendations Still Fail to Result in Action: A National 10-year Follow-up of Investigative Interviews in CSA Cases. Applied Cognitive Psychology 29 (5): 661-668.

Josselyn, Sheena, and Paul Frankland. 2012. Infantile amnesia: A neurogenic hypothesis. Learning \& Memory 19: 423-433.

Korkman, Julia, Pekka Santtila, and Kenneth Sandnabba. 2006. Dynamics of Verbal Interaction Between Interviewer and Child in Interviews with Alleged Victims of Child Sexual Abuse. Scandinavian Journal of Psychology 47: 109-120.

Lamb, Michael. 2016. Difficulties Translating Research on Forensic Interview Practices to Practitioners: Finding Water, Leading Horses, but Can We Get Them to Drink? American Psychologist 71 (8): 710-718. 
Lamb, Michael, Irit Hershkowitz, and Thomas Lyon. 2013. Interviewing Victims and Suspected Victims Who Are Reluctant to Talk. APSAC Advisor 4: 16-19.

Lamb, Michael, David La Rooy, Lindsay Malloy, and Carmit Katz. 2011. Children's Testimony: A Handbook of Psychological Research and Forensic Practice. London: Wiley.

Lamb, Michael, Kathleen Sternberg, and Phillip Esplin. 1998. Conducting Investigative Interviews of Alleged Sexual Abuse Victims. Child Abuse and Neglect 22: 813-823.

Lamb, Michael, Irit Hershkowitz, Yael Orbach, and Phillip Esplin. 2008. Tell me what happened: Structured investigative interviews of child victims and witnesses. Hoboken, NJ: Wiley.

Lamb, Michael, Irit Hershkowitz, Kathleen Sternberg, Meir Hovav, Talna Manor, and Liora Yidilevitch. 1996. Effects of investigative utterance types on Israeli children's responses. International Journal of Behavioral Development 19: 627-637.

Lamb, Michael, Kathleen Sternberg, Yael Orbach, Irit Hershkowitz, Dvora Horowitz, and Phillip Esplin. 2002. The Effects of Intensive Training and Ongoing Supervision on the Quality of Investigative Interviews with Alleged Sex Abuse Victims. Applied Developmental Science 6: 114-125.

Lamb, Michael, Irit Hershkowitz YaelOrbach, Phillip Esplin, Dvora Horowitz, and Dvora. 2007. A structured Forensic Interview Protocol Improves the Quality and Informativeness of Investigative Interviews with Children: A Review of Research Using the NICHD Investigative Interview Protocol. Child Abuse \& Neglect 31: 1201-1231.

Lamb, Michael, Yael Orbach, Irit Hershkowitz, Dvora Horowitz, and Craig Abbott. 2007. Does the Type of Prompt Affect the Accuracy of Information Provided by Alleged Victims of Abuse in Forensic Interviews? Applied Cognitive Psychology 21: 1117-1130.

La Rooy, David, Carmit Katz, and Lindsay Malloy. 2010. Do we need to rethink guidance on repeated interviews? Psychology, Public Police, and Law 16: 373-392.

La Rooy, David, Lindsay Malloy and Michael Lamb. 2011. The Development of Memory in Childhood. In Children's Testimony: A Handbook of Psychological Research and Forensic Practice. eds. M.E. Lamb, D. J. La Rooy, L. C. Malloy, and C. Katz, 2nd ed, 49-68. New York: Wiley-Blackwell.

La, Rooy, Michael Lamb David, and Margaret-Ellen Pipe. 2009. Repeated Interviewing: Acritical Evaluation of the Risks and Potential Benefits. In Child Sexual Abuse: Research Evaluation and Testimony for the Courts, eds. K. Kuehnle, and M. Connell. New Jersey: Wiley. 
Leander, Lina, Sven Christianson, and Pär-Anders Granhag. 2007. A Sexual Abuse Case Study: Children's Memories and Reports. Psychiatry, Psychology and Law 14 (1): 120-129.

Lewis, Tiffany, Bianca Klettke, and Andrew Day. 2014. The Influence of Medical and Behavioral Evidence on Conviction Rates in Cases of Child Sexual Abuse. Journal of Child Sexual Abuse 23: 431-441.

London, Kamala, Maggie Bruck, Daniel Schuman and Stephen Ceci. 2005. Disclosure of Child Sexual Abuse. What Does the Research Tell Us About the Ways That Children Tell? Psychology, Public Policy and Law (1): 194-226, doi:10.1037/1076-8971.11.1.194.

London, Kamala, Maggie Bruck, Daniel Wright and Stephen Ceci. 2008. Review of the Contemporary Literature on How Children Report Sexual Abuse to Others: Findings, Methodological Issues, and Implications for Forensic Interviewers. Memory 16 (1): 29-47. doi:10.1080/09658210701725732.

Melnyk, Laura, Angela Crossman, and Matthew Sculling. 2007. The suggestibility of children's memory. In The Handbook of Eyewitness Psychology, vol I: Memory for Events, eds. M.P. Toglia, J.D. Read, D.F. Ross, and R.C.L. Lindsat, 401-427. Mahwah, NJ, US: Lawrence Erlabuam Associates Publishers.

Michael, Lamb. Irit Hershkowitz, Kathleen Sternberg, Phillip Esplin, Meir Hovav, Talma Manor, and Liora Yudilevitch. 1996. Effects of Investigative Utterance Types on Israeli Children's Responses. International Journal of Behavioral Development 19: 627-637.

Newcombe, Nora, Marianne Lloyd and Kristin Ratliff. 2007. Development of Episodic and Autobiographical Memory: A Cognitive Neuroscience Perspective. In Advances in Child Development and Behavior, ed. R.V. Kail, vol. 35. 37-85. London, England: Elsevier.

Orbach, Yael, Irit Hershkowitz, Michael Lamb, Kathleen Sternberg, Phillip Esplin, and Dvora Horowitz. 2000. Assessing the Value of Structured Protocols for Forensic Interviews of Alleged Abuse Victims. Child Abuse and Neglect 24: 733-752.

Ornstein, Peter, Lynne Baker-Ward, Betty Gordon, and Kathy Merritt. 1997. Children's Memory for Medical Experiences: Implications for Testimony. Applied Cognitive Psychology 11: 87-104.

Peterson, Carole, and Kelly Warren. 2009. Injuries Emergency Rooms and Children's Memory: Factors Contributing to Individual Differences. In Emotion and Memory in Development: Biological Cognitive and Social 
Considerations, eds. J. Quas, and R. Fivush, 60-85. Oxford: Oxford University Press.

Quas, Jodi, Amy Bauer and Thomas Boyce. 2004. Physiological Reactivity, Social Support, and Memory in Early Childhood. Child Development 75: 797-814. doi:10.1111/j.1467-8624.2004.00707.x.

Roozendaal, Benno, Bruce McEwen, and Sumatra Chattarji. 2009. Stress, Memory and the Amygdala. Nature Reviews Neuroscience 10: 423-433. doi: $10.1038 / \mathrm{nrn} 2651$.

Rush, Elizabeth, Jodi Quas, Liona Yim, Mariya Nikolayev, Steven Clark, and Rakel Larson. 2014. Stress, Interviewer Support, and Children's Eyewitness Identification Accuracy. Child Development 85 (3): 1292-1305. doi:10.1111/cdev.12177.

Santtila, Pekka, Julia Korkman, and Kenneth Sandnabba. 2004. Effects of interview phase, repeated interviewing, presence of a support person, and anatomically detailed dolls on child sex abuse interviews. Psychology, Crime \& Law 10: 21-35.

Schneider, Wolfgang, and David Bjorklund. 2003. Memory and knowledge development. In Handbook of Developmental Psychology, eds. J. Valsiner, and K. Connolly, 370-403. London: Sage.

Schneider, Wolfgang, and Michael Pressley. 2013. Memory Development Between Two and Twenty. New Jersey: Lawrence Erlbaum Associates.

Simcock, Gabrielle, and Harlene Hayne. 2002. Breaking the Barrier? Children Fail to Translate Their Preverbal Memories into Language. Psychological Science 13: 225-231.

Smeets, Tom, Henry Otgaar, Ingrid Candel, and Oliver Wolf. 2008. True or False? Memory is Differentially Affected by Stress-induced Cortisol Elevations and Sympathetic Activity at Consolidation and Retrieval. Psychoneuroendorinologi 33 (10): 1378-1386.

Smith, Daniel, Elizabeth Letourneau, Benjamin Saunders, Dean Kilpatrick, Heidi Resnick, and Connie Best. 2000. Delay in Disclosure of Childhood Rape: Results from a National Survey. Child Abuse and Neglect 24 (2): 273287.

Squire, Larry. 2004. Memory Systems of the Brain: A Brief History and Current Perspective. Neurobiology of Learning and Memory 82: 171-177.

Sternberg, Kathleen, Michael Lamb, Graham Davies, and Helen Westcott. 2001. The Memorandum of Good Practice: Theory versus application. Child Abuse and Neglect 25: 669-681.

Sternberg, Kathleen, Michael Lamb, Irit Hershkowitz, Phillip Esplin, Allison Redlich, and Naomi Sunshine. 1996. The Relationship Between 
Investigative Utterance Types and the Informativeness of Child Witnesses. Journal of Applied Developmental Psychology 17: 439-451.

Tulving, Endel. 1985. Memory and Consciousness. Psychologie Canadienne 26: $1-12$.

Warren, Amya, Cara Woodall, Marney Thomas, Michael Nunno, Jennifer Keeney, Susan Larson, and Julie Stadfeld. 1999. Assessing the Effectiveness of a Training Program for Interviewing Child Witnesses. Applied Developmental Science 3: 128-135.

Westcott, Helen, and Sally Kynan. 2006. Interviewer practice in investigative interviews for suspected child sexual abuse. Psychology, Crime and Law 12: $367-382$.

Open Access This chapter is licensed under the terms of the Creative Commons Attribution 4.0 International License (http://creativecommons. org/licenses/by/4.0/), which permits use, sharing, adaptation, distribution and reproduction in any medium or format, as long as you give appropriate credit to the original author(s) and the source, provide a link to the Creative Commons license and indicate if changes were made.

The images or other third party material in this chapter are included in the chapter's Creative Commons license, unless indicated otherwise in a credit line to the material. If material is not included in the chapter's Creative Commons license and your intended use is not permitted by statutory regulation or exceeds the permitted use, you will need to obtain permission directly from the copyright holder.

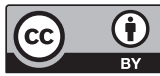

